\title{
Crop Identification by Using Seasonal Parameters Extracted from Time Series Landsat Images in a Mountainous Agricultural County of Eastern Qinghai Province, China
}

\author{
Xia Zhao ${ }^{1}$, Xingchun Wang ${ }^{1}$, Guangchao Cao ${ }^{1}$, Kelong Chen ${ }^{1}$, Wenjia Tang ${ }^{2} \&$ Zhijun Zhang ${ }^{2}$ \\ ${ }^{1}$ College of Life and Geographic Sciences, Key Laboratory of Qinghai Provine on Physical Geography and \\ Environmental Process, Qinghai Normal University, Xining, China \\ ${ }^{2}$ Remote Sensing Center for Eco-Environmental Monitoring of Qinghai Province, Xining, China \\ Correspondence: Xia Zhao, College of Life and Geographical Sciences, Qinghai Normal University, Xining \\ 810008, China. Tel: 86-139-9706-0081. E-mail: zhaoxia@qhnu.edu.cn
}

$\begin{array}{ll}\text { Received: January 25, } 2017 & \text { Accepted: February 22, } 2017 \quad \text { Online Published: March 15, } 2017 \\ \text { doi:10.5539/jas.v9n4p116 } & \text { URL: https://doi.org/10.5539/jas.v9n4p116 }\end{array}$

The research is financed by the Department of Science \& Technology in Qinghai Province, China (Grant No. 2013-Z-936Q).

\begin{abstract}
Time series vegetable indexes (Vis) have been evidenced a useful data to extract vegetable phenology and identify crop types. This paper conducted such a research in Qinghai Province by using Landsat TM images, via four steps, i) sampling single-crop plots and extracting crop spectrums based on pure signle-crop pixels; ii) building time-series vegetable indexes by using Landsat 8 TM images (2013-2014); iii) extracting seasonal parameters according to algorithms defined in TIMESAT program; vi) generating a decision tree for identifying crop types and validate classification accuracy via ground investigation. The results indicate that crops planted in a larger continuous range, such as spring wheat, potato and rapeseed, achieved an acceptable accuracy of above $70 \%$, while crops planted too dispersedly (like broad bean, which is often inter-planted with other crops) or with a too smaller planting range (like barley), remained a poor recognition rates (below 50\%). The value of this work lies in it displayed not only the classification accuracy of crop types in this region by using such methodology, but also the feasibility of integrating VIs calculation, seasonal parameter extracting and decision tree generation into one computer program, which is highly desired in this region.
\end{abstract}

Keywords: time-series VIs, seasonal parameters, crop identification, eastern Qinghai

\section{Introduction}

Wide-ranging, long-term, and spatially accurate cropland classification data is a valuable source of information for government agencies, private sector organizations, scientists, educators, and others who use land-cover information. Crop mapping on an annual basis can provide improved estimats of near real time changes in crop production and can greatly benefit strategic planning in agro-ecosystems, crop type maps are among the most important datasets in crop management and yield estimation (Boryan, Yang, \& Mueller, 2011; Shao, Lunetta, Ediriwickreme, \& Liames, 2010). Remote sensing data has become an efficient and reliable approach of deriving such information across large area where field-based methods are of limited utility; many researches have demonstrated successful application for various agricultural usages (Chen \& Zhuang, 2012; Oetter, Cohen, Berterretche, Maiersperger, \& Kennedy, 2000; Wall, Laricque, \& Léger, 2008).

Phenology is the nature's calendar on periodic biological events and their controlling factors of environment, many interactions in nature depend on timing. In fact, phenology affects nearly all aspects of the environment, including the abundance, distribution, and diversity of organisms, ecosystem services, food webs, and the global cycles of water and carbon. For most plants species, phenological event like onset of green, mature and senescence often occurs at a relatively stable time node over a long time period, therefore, phenological characteristic is frequently used as an auxiliary information or even priority metric to identify plant type, such as distinguish evergreen forest from seasonal forest and trees from shrubs etc (Reed, Brown, Vanderzee, \& Ohlen, 
1994; White, Hoffman, Hargrove, \& Nemani, 2005). Time-series Vegetation indices (VIs) derived from various remote sensing images has become one of the most promising way for such purpose, those quantitatively constructed indicators showed a high correlation between vegetation vigor/greenness and their overall spectral properties, which is generally estimated as a ratio or combination of several spectral bands via enhancing spectral sensitivity of objected vegetation characteristics (leaf chlorophyll content, leaf area, canopy cover and structure etc.) while weakening environmental factors (Simonneaux et al., 2008; Gong \& Shi, 2003).

In the field of crop mapping, seasonal parameters, like the starting and ending of the season, seasonal amplitude, seasonal length etc., that derived from various time-series VIs, have being used successfully in discriminating most of stable crops, such as wheat, corn, soybean and sorghum etc. (Zhong, Hawkins, Biging, \& Gong, 2011; Patel \& Oza, 2015; Oteros, García-Mozo, Botey, \& Galán, 2015). However, the classification accuracy of such research usually depends on the matching situation between image resolution and fields size, generally speaking, coarse spatial resolution $(250-1000 \mathrm{~m})$ with high temporal resolution (1-3 days) images are more suitable for large scale observation, while moderate spatial resolution $(30 \mathrm{~m})$ with lower temporal resolution (16 days) images are more suitable for local scale application. Because of such limitation, most of existing researches focused on plain area where the size of crop land is usually several times larger than image resolution (e.g., 15-30 hectare crop lands matches to 250 m MODIS image) (Fischer, 1994; Wardlow \& Egbert, 2008; Xu, Yang, Long, \& Wang, 2013).

On the other hand, from the view of local food security and global agricultural diversity, crops planted in mountainous area cannot be ignored, where crop land is usually constrained within or along river valley with a relatively smaller field size and discontinuous spatial distribution, therefore traditional agricultural survey is extremely difficult to implement and remote sensing investigation on crops phenology is highly desired. Qinghai-Tibet plateau is one of such region which is the highest crop planting region in the world (Zhang et al., 2008; Brown \& Waldron, 2013). Inspired by above facts, this paper conducted such a research in a major crop production county in Qinghai Province, aming to test the feasibility of extracting seasonality parameters from 30 $\mathrm{m}$ resolution TM images, and building growth curves for each type of crop and obtaining decision rules for discriminating them as well.

\section{Materials and Methods}

\subsection{Research Area}

We selected a typical agricultural watershed in eastern Qinghai-Tibet Plateau (Figure 1a), which belongs a semi-wet climate region with an elevation range of $2102 \mathrm{~m}-4582 \mathrm{~m}$ (Figure 1b), average annual temperature of 6.3 centigrade, average annual precipitation of 587 millimeters, and a short growth season of less than 3 months, the stable crops commonly planted here including spring wheat, highland barley, rapeseed, potato and broad bean. Agricultural land in this region accounts for $30 \%$ of total land area, half of them are cultivated as cropland (Figure 1c). Among those cropland, about 20\% located in river valleys where the elevation is below 2350 meter that can be irrigated fully, about $40 \%$ located in lower elevation hillsides (2350-2450 meter) that can be irrigated partly, the remaining $40 \%$ located in higher elevation hillsides (2450-2650 meter) that can't be irrigated and therefore belongs to totally rainfed cropland (Figure 1c).

Given the consideration of field size that most farmers planted for single crop is much smaller than 0.2 hectare, which can't match the minimum requirement of TM images interpretation. A demonstration project region of China's National Standard Farmland in Datong County (Agriculture and Animal Husbandry Bureau of DaTong County, 2013) was selected as sampling source of three main crops, spring wheat, potato and broad bean, where 14 plots was picked up as the single-crop plots for them. Another 5 plots was picked up for barley and rapeseed from northern part neighboring region for the sake of keeping consistent climate conditions for crops tested in this work, where there are no demonstration plots for them (Figure 1d). 


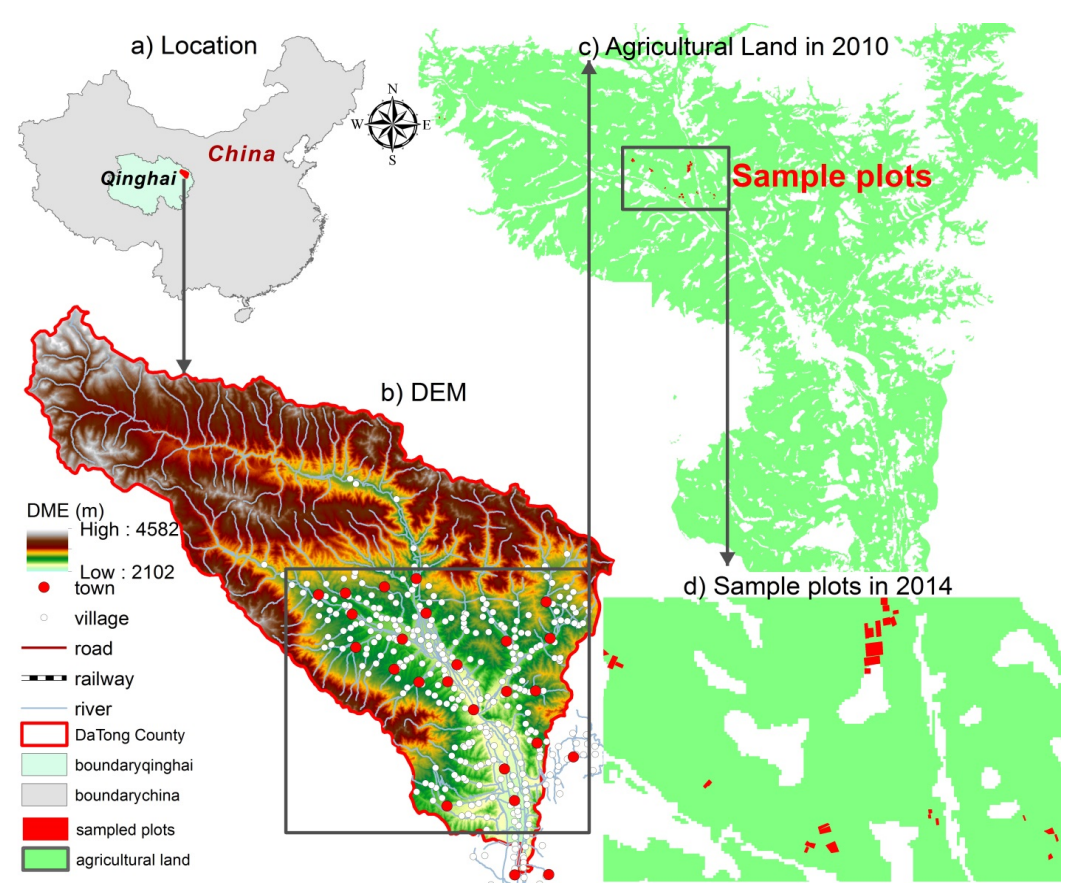

Figure. 1 Agricultural land and sample plots for major crops in research area

\subsection{Workflow}

According to general rules of remote sensing data application and the main focus of this paper, we designed a three-step procedure (Figure 2) to fulfill this task. The key idea is applying a known set of crop seasonal parameters derived from ground-true sampling of single crops into classification of those unknown crop type plots. The scientific evidence behind this lies in the fact of although seasonal parameters of each crop is varied across years due to climate fluctuation and changes of field managements, however, the general rules of greening, browning and harvesting tended to be consistent within the same sort of crops, if there is no significant changes in climate characteristics (Sakamoto et al., 2005; Odebweller, 1984).

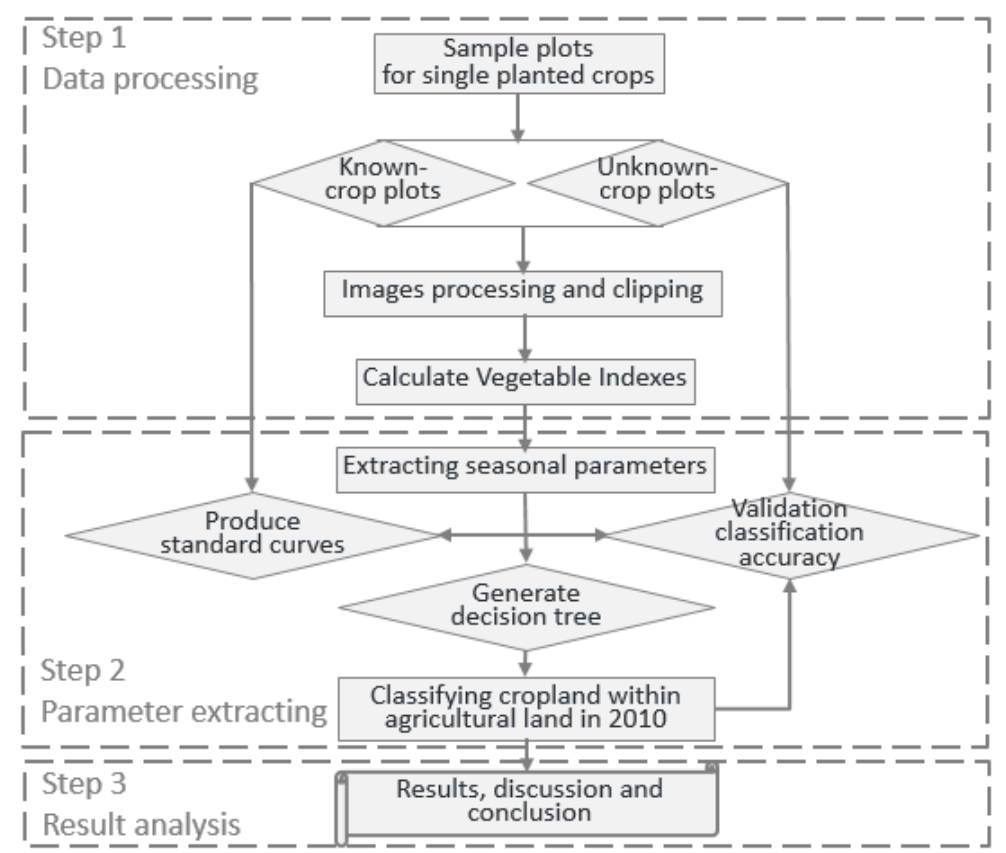

Figure 2. Workflow of crop identification and classification 


\subsection{Data Collection}

\subsubsection{Image Data}

Several time-series multispectral data are available for monitoring plant phenology at a continuous temporal trajectory, which can be roughly sorted into three categories according to their resolution and obtaining method. First, freely downloaded higher temporal resolution (1-3 days) but coarse spatial resolution $(250-1000 \mathrm{~m})$ sensors like Moderate Resolution Imaging Spectroradiometer (MODIS) and Advanced Very High Resolution Radiometer (AVHRR). Second, freely downloaded moderate spatial resolution (10-30 m) but coarse temporal resolution (16 days) sensors like Landsat Thematic Mapper (TM/ETM+) and Operational Land Imager (OLI). Third, acquisition data of both high temporal resolution (1 day) and spatial resolution (6 m) sensor, like Systeme Probatoire d'Observation de la Terre (SPOT). Given the combined consideration of temporal-spatial resolution and image accessibility, Landsat TM images is a better choice for such research in this region.

As one of the most valuable datasets available for mapping and monitoring the Earth surface over 40 years, Landsat sensors provide continuous images at a 16-day time step with a resolution of 30 meter at multispectral bands, which is widely used in time series VIs analyses. However, those optical sensors carried by Landsat 4, 5 , and 7 are designed without specific bands for cloud detection, which made them hard to detect these high-altitude, cold and wispy clouds in mountain area. Landsat 8 fixed this deficiency by adding a new band of Short Wave Infrared (Band 9, 1.36-1.39 $\mu \mathrm{m}$ ) to Thermal Infrared Sensors (TIRS), which is especially helpful for detecting cirrus clouds (Cohen \& Goward, 2004; Roy et al., 2014). Given above consideration, Landsat 8 OLI images is selected as the data source for deriving time-series VIs in this paper, and the initial images (the research area is totally covered by one scene at row 132 and path 34) available from USGS website for this region during 2013-2015 is 59 scenes (Table 1).

Table 1. Landsat 8 images available in research area during 2013-2015

\begin{tabular}{|c|c|c|c|c|c|c|c|c|}
\hline \multicolumn{3}{|c|}{ Year 2013 (14) } & \multicolumn{3}{|c|}{ Year $2014(22)$} & \multicolumn{3}{|c|}{ Year 2015 (23) } \\
\hline Date & $\begin{array}{l}\text { Day of } \\
\text { Year }\end{array}$ & $\begin{array}{l}\text { Cloud Coverage } \\
(\%)\end{array}$ & Date & $\begin{array}{l}\text { Day of } \\
\text { Year }\end{array}$ & $\begin{array}{l}\text { Cloud Coverage } \\
(\%)\end{array}$ & Date & $\begin{array}{l}\text { Day of } \\
\text { Year }\end{array}$ & $\begin{array}{l}\text { Cloud Coverage } \\
(\%)\end{array}$ \\
\hline & & & & & & 2015-01-09 & 9 & 8.50 \\
\hline & & & 2014-02-09 & 22 & 3.39 & $2015-01-25$ & 25 & 8.95 \\
\hline & & & 2014-02-07 & 38 & 16.64 & $2015-02-10$ & 41 & 14.51 \\
\hline & & & $2014-02-23$ & 54 & 11.30 & $2015-02-26$ & 57 & 51.88 \\
\hline & & & 2014-03-11 & 70 & 74.37 & 2015-03-14 & 73 & 5.76 \\
\hline & & & 2014-03-27 & 86 & 20.51 & 2015-03-30 & 89 & 13.84 \\
\hline & & & 2014-04-12 & 102 & 29.42 & 2015-04-15 & 105 & 10.04 \\
\hline \multirow[t]{2}{*}{ 2013-04-25 } & 115 & 0.50 & 2014-04-28 & 118 & 4.76 & 2015-05-01 & 121 & 11.98 \\
\hline & & & 2014-05-14 & 134 & 59.74 & $2015-05-17$ & 137 & 10.56 \\
\hline $2013-05-27$ & 147 & 36.79 & $2014-05-30$ & 150 & 59.52 & 2015-06-02 & 153 & 83.85 \\
\hline $2013-06-12$ & 163 & 6.95 & 2014-06-15 & 166 & 35.75 & 2015-06-18 & 169 & 49.63 \\
\hline \multirow[t]{2}{*}{$2013-06-28$} & 179 & 0.10 & 2014-07-01 & 182 & 33.44 & 2015-07-04 & 185 & 45.43 \\
\hline & & & 2014-07-17 & 198 & 0.94 & $2015-07-20$ & 201 & 26.19 \\
\hline 2013-07-30 & 211 & 4.19 & 2014-08-02 & 214 & 22.19 & $2015-08-05$ & 217 & 30.71 \\
\hline $2013-08-15$ & 227 & 38.28 & 2014-08-18 & 230 & 2.57 & $2015-08-21$ & 233 & 2.93 \\
\hline $2013-08-31$ & 243 & 31.66 & 2014-09-03 & 246 & 6.70 & 2015-09-06 & 249 & 2.70 \\
\hline 2013-09-16 & 259 & 16.10 & 2014-09-19 & 262 & 12.55 & $2015-09-22$ & 265 & 9.25 \\
\hline $2013-10-02$ & 275 & 3.63 & 2014-10-05 & 278 & 1.98 & $2015-10-08$ & 281 & 24.77 \\
\hline $2013-10-18$ & 291 & 49.71 & $2014-10-21$ & 294 & 5.06 & $2015-10-24$ & 297 & 37.25 \\
\hline 2013-11-03 & 307 & 16.59 & 2014-11-06 & 310 & 25.81 & 2015-11-09 & 313 & 29.58 \\
\hline 2013-11-19 & 323 & 6.26 & $2014-11-22$ & 326 & 82.51 & $2015-11-25$ & 329 & 11.92 \\
\hline $2013-12-05$ & 339 & 7.89 & 2014-12-08 & 342 & 11.12 & $2015-12-11$ & 345 & 12.48 \\
\hline $2013-12-21$ & 355 & 19.04 & $2014-12-24$ & 358 & 16.63 & $2015-12-27$ & 361 & 11.88 \\
\hline
\end{tabular}




\subsubsection{Ground Data}

Using ground-true data to assistant interpretation of image data is a common way to improve research accuracy, general experience suggests a sampling strategy using smaller-size units but a larger number of samples provide more precise estimates than a strategy using larger-size units but a smaller number of samples with an equivalent total area (Stehman, Sohl, \& Loveland, 2005). This is fulfilled by consulting local agricultural managers to screen a numbers of candidate fields for each crops firstly, then followed with a two-step sampling scheme, that is: i) to sample a set of single pure crop plots that can be served as reference standards of crop identification, which is fulfilled at 2014 winter when the field shape and size, as well as crop type can be observed clearly, 19 plots are collected under the area requirement of each plot larger than 0.5 hectare, by which a minimum pixel amount of 3 can be guaranteed with a 30 meter resolution image; ii) to verify a set of unknown crop plots that identified as certain crops according to classification rules that established in first step, which is fulfilled at 2014 winter and 2015 winter by labeling 3-5 plots for each crop and verifying actual crops that planted in that plots.

\subsubsection{Auxiliary Data}

A recent land use/cover map of 2010 (Figure 1c) is used as a mask to screen possible crop land parcels in 2015 so that scaling down verification scope. This map is provided by Remote Sensing Center of EPA in Qinghai Province, which is served as a base map for "Eco-Environmental Change Evaluation of first ten years in 21 Century in Qinghai Province". Other data including digital elevation map and basic geographical map are provided by local Geographical Information Center.

\section{Data Processing and Results}

\subsection{Image Processing}

Multitemporal satellite-image datasets are affected by different sources of noise related to the stability of sensors, changes in satellite responsivity, changes in illumination, atmospheric effects, etc., as the homogeneity of time series of satellite images is crucial when studying abrupt or gradual changes in vegetation cover, several protocols have been proposed in their pre-processing: i) geometric correction, ii) radiometric calibration, iii) atmospheric correction, iv) topographic correction, and v) relative radiometric normalization (Bodart et al., 2011). As the standard Level-1 products of Landsat 8 are delivered with already geometrically corrected, we conducted three other corrections before time-series VIs extraction, all those processing are carried out with ENVI 5.3 software.

\subsection{VIs Calculation and Time-Series Building}

\subsubsection{VIs Selection and Calculation}

More than 150 VIs have been published in scientific literature, but only a small subset has been systematically tested enabling substantial biophysical basis and general applicability. Among them, Couples of VIs have been evidenced suitable for usage of crop classification, including Enhanced Vegetation Index (EVI), Green Vegetation Index (GVI), Leaf Area Index (LAI), Normalized Difference Vegetation Index (NDVI), Red Green Ratio Index (RGRI), Soil Adjusted Vegetation Index (SAVI) and WorldView Improved Vegetation Index (WVVI) etc. Three of them, namely NDVI, EVI and SAVI (Bannari, Morin, Bonn, \& Huete,1995; Yang, Di, Yu, \& Chen, 2011), were selected to build time-series VIs based on accounts of: i) they are mostly used VIs in crop related research, ii) they have better discriminating ability on land cover phases of crop lands such as dense green crops, sparse vegetation and bare soil, iii) they are derivable from bands calculation of Landsat 8 TM images.

NDVI is generally calculated as the normalized difference between near-infrared and red bands [NDVI $=(\mathrm{NIR}-$ RED)/(NIR + RED)]. It is constructed on the fact that chlorophyll absorbs RED whereas the mesophyll leaf structure scatters NIR, and the NDVI value thus range from -1 to 1 where negative values correspond to an absence of vegetation. Although NDVI has been demonstrated usefulness in many relative studies, however, in some situation, the relationship between NDVI and vegetation can be biased in sparsely vegetated areas (e.g. arid to semi-arid zone) and dense canopies (e.g. tropic forest).For example, in sparsely vegetated areas with a leaf area index (LAI) of $<3$, the NDVI is influenced mainly by soil reflectance while for LAI $>6$ (densely vegetated areas), the relationship between the NDVI and NIR becomes saturate, therefore, other vegetation indexes like SAVI might be more appropriate for those areas (Boehmer, 1996; Ke, Im, Lee, Gong, \& Ryu, 2015).

Soil Adjusted Vegetation Index (SAVI) is similar to NDVI [SAVI $=1.5 \times(\mathrm{NIR}-\mathrm{Red}) /(\mathrm{NIR}+\mathrm{Red}+0.5)$ ], but it suppresses the effects of soil pixels by using a canopy background adjustment L, which is a function of vegetation density and often requires prior knowledge of vegetation amounts. This index is best used in areas with relative sparse vegetation where soil is visible through the canopy; however, it requires local calibration because it is difficult to predict how soil effects are manifested within large pixel areas, where many different 
types of soils and vegetation are aggregated together. For general application, an optimal value of $\mathrm{L}=0.5$ is often adopted as the most likely account of soil background variations (Huete, 1988).

Enhanced Vegetation Index (EVI) is developed to improve the NDVI by optimizing the vegetation signal regions, it uses the blue reflectance region to correct for soil background signals and to reduce atmospheric influences, including aerosol scattering. This index $[\mathrm{EVI}=2.5 \times(\mathrm{NIR}-\mathrm{Red}) /(\mathrm{NIR}+6 \times \mathrm{Red}-7.5 \times$ Blue +1$)]$ provides complementary information about the spatial and temporal variations of vegetation, while minimizing many of the contamination problems present in the NDVI, such as those associated with canopy background and residual aerosol influences. Compared to NDVI, which is chlorophyll sensitive and responds mostly to RED variations, the EVI is more NIR sensitive and responsive to canopy structural variation, including LAI, canopy type and architecture, which is also more useful in regions of higher LAI where NDVI becomes saturated easily (Huete et al., 2002).

\subsubsection{Time-Series VIs Building}

Although there are 23 scenes of Landsat 8 OLI images (at 16-day step) in a year theoretically, it is actually impossible to build a complete 23 scenes of time-series images within each year because of possible sensor dropping out and heavy cloud contamination or combination of both, therefore an interpolation of missing data is usually required to obtain a complete time-series dataset. Limited by the amount of available images and their cloud cover quality, this paper developed three assumptions to build a complete time-series dataset based on following facts: i) there are no crop growing in field during winter (end of October to early March) in research area, which makes it is acceptable to fill missing data of this period directly with any available data in other years; ii) all sampled plots are cultivated with same crops in 2013 and 2014 according to filed investigation, which make it reasonable to fill missing data of corresponding date with each other under a stable climate condition where precipitation and temperature keeps stable; iii) all missing values that occurred in continuous intervals can be interpolated with neighbor values by using method of double cumulative analysis and those in discontinuous intervals can be filled with an average value of neighboring time nodes.

\subsection{Curve Fitting and Parameter Extracting}

As a raw dataset of time-series VI contains not only useful signal of seasonal, but also changes that occurred gradually or abruptly, and combined noises originated from remnant geometric errors, atmospheric scatter or cloud effects, therefore, trend separation and noise removing are often required before any further usage. A number of methods have been developed for such purposes, among which, curve fitting techniques showed remarkable effects on spurious observations removing, missing values interpolation and obtaining of equal-interval observations as well, which is essential for time-series data rooted phenological research (Verbesselt, Hyndman, Newnham, \& Culvenor, 2010; Chen et al., 2004).

TIMESAT (Jönsson \& Eklundh, 2004) (version 3.2, http://web.nateko.lu.se/timesat/timesat.asp) is widely used software in this field, which offers not only predefined seasonal parameters like the dates of season starting and ending, VIs values of base level and peak level, dates of $20 \%$ and $80 \%$ biomass and corresponding VIs values, seasonal length and seasonal amplitude etc., which can be used as criterions for crop discrimination; but also three mostly used fitting methods that used in phenology researches, such as adaptive Savitzky-Golay filtering (SG), Asymmetric Gaussian (AG) and Double Logistic function (DL). In view of the complicity of developing a computer program for those three curve fitting methods, this paper adopted a TIMESAT-rooted approaches to get the fitted curves for each crop, which is then be served as input data for seasonal parameter extracting. The results are listed as Figure 3 and Table 2. 


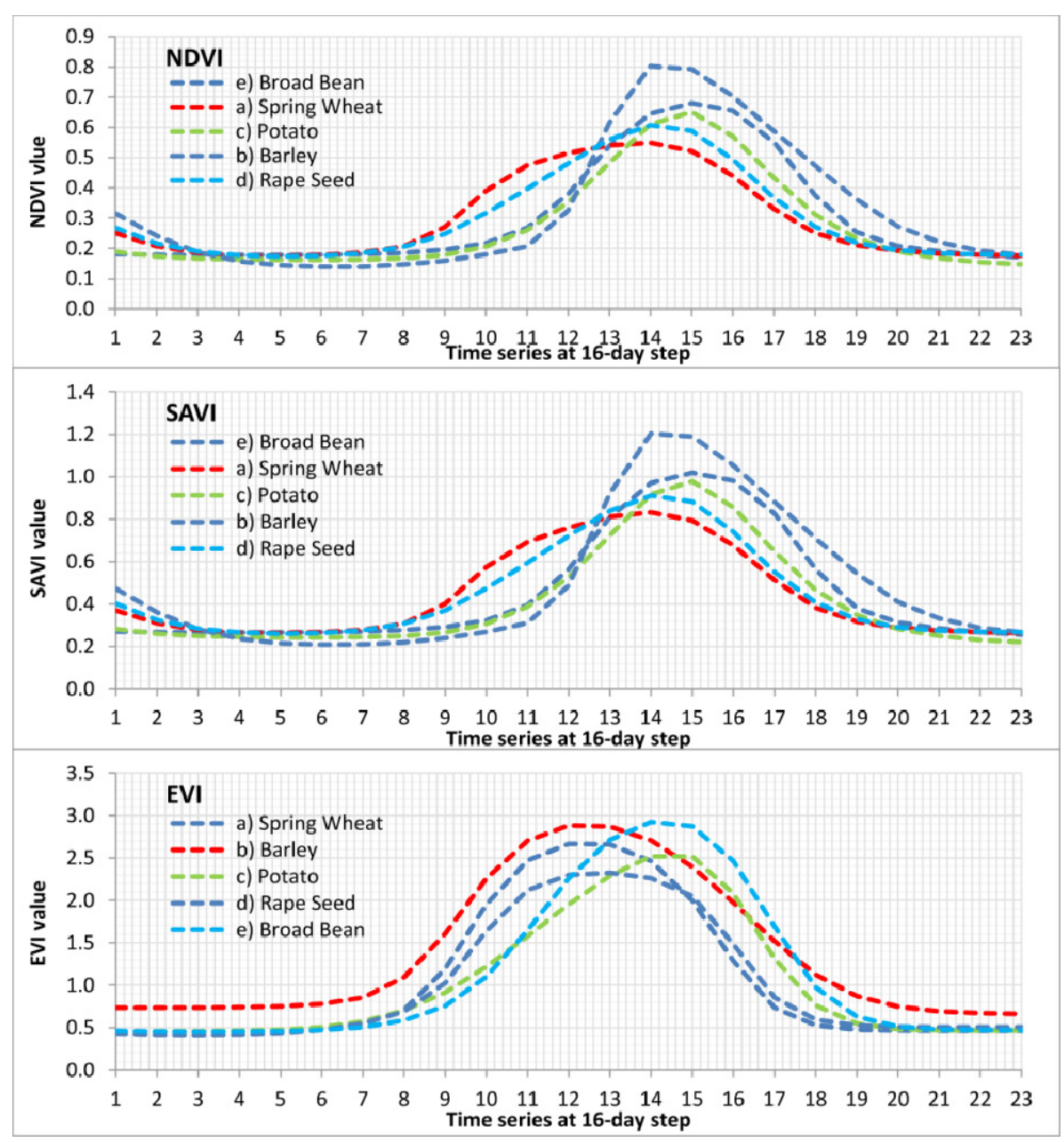

Figure 3. Fitted crop curves for three VIs using Double-Logistic filter algorithm derived from TIMESAT software

Table 2. Seasonal parameters and variation ranges of NDVI for each crop

\begin{tabular}{|c|c|c|c|c|c|c|c|c|c|c|c|c|c|c|c|}
\hline \multirow{2}{*}{ Crop Type } & \multicolumn{3}{|c|}{ Start Day } & \multicolumn{3}{|c|}{ End Day } & \multicolumn{3}{|c|}{ Lengh of Day } & \multicolumn{3}{|c|}{ Peak NDVI } & \multicolumn{3}{|c|}{ Amplitude of NDVI } \\
\hline & $\min$ & mean & $\max$ & $\min$ & mean & $\max$ & $\min$ & mean & $\max$ & $\min$ & mean & $\max$ & $\min$ & mean & $\max$ \\
\hline Spring Wheat & 93 & 100 & 110 & 204 & 206 & 207 & 95 & 106 & 114 & 0.79 & 0.82 & 0.84 & 0.75 & 0.78 & 0.81 \\
\hline Barley & 44 & 53 & 61 & 200 & 219 & 239 & 156 & 167 & 178 & 0.83 & 0.83 & 0.84 & 0.78 & 0.78 & 0.78 \\
\hline Potato & 125 & 125 & 125 & 234 & 234 & 235 & 109 & 109 & 110 & 0.80 & 0.82 & 0.86 & 0.77 & 0.79 & 0.82 \\
\hline Rape Seed & 61 & 72 & 94 & 200 & 212 & 236 & 139 & 140 & 143 & 0.76 & 0.77 & 0.78 & 0.72 & 0.74 & 0.75 \\
\hline Broad Bean & 61 & 83 & 110 & 200 & 218 & 237 & 123 & 136 & 144 & 0.77 & 0.82 & 0.86 & 0.73 & 0.78 & 0.83 \\
\hline
\end{tabular}

\subsection{Decision Tree and Crop Classification}

Decision tree (DT) is an effective tool used in various classifications and mapping field (Pal \& Mather, 2003; Lees \& Ritman, 1991), given the fact of lacking of crops spectral data and limited sampled plots, this paper adopted a three steps approach to generate a decision tree, which is then be used as classification criterions for crop identification within unknown crop type land in this region, which is: i) generate an original decision tree by input all available pixels that has known crop types via field investigation; ii) verify classification accuracy by comparing crop types assigned by decision tree with that of field investigation, and excludepixels with classification errors; iii) construct a decision tree that can be served as prediction rules for crop identification within unknown crop type pixels, which is generated from above two steps. This work is finished in software Clementine 12.0 by using C5.0 algorithm, and the final decision tree is displayed as below (Figure 4). 


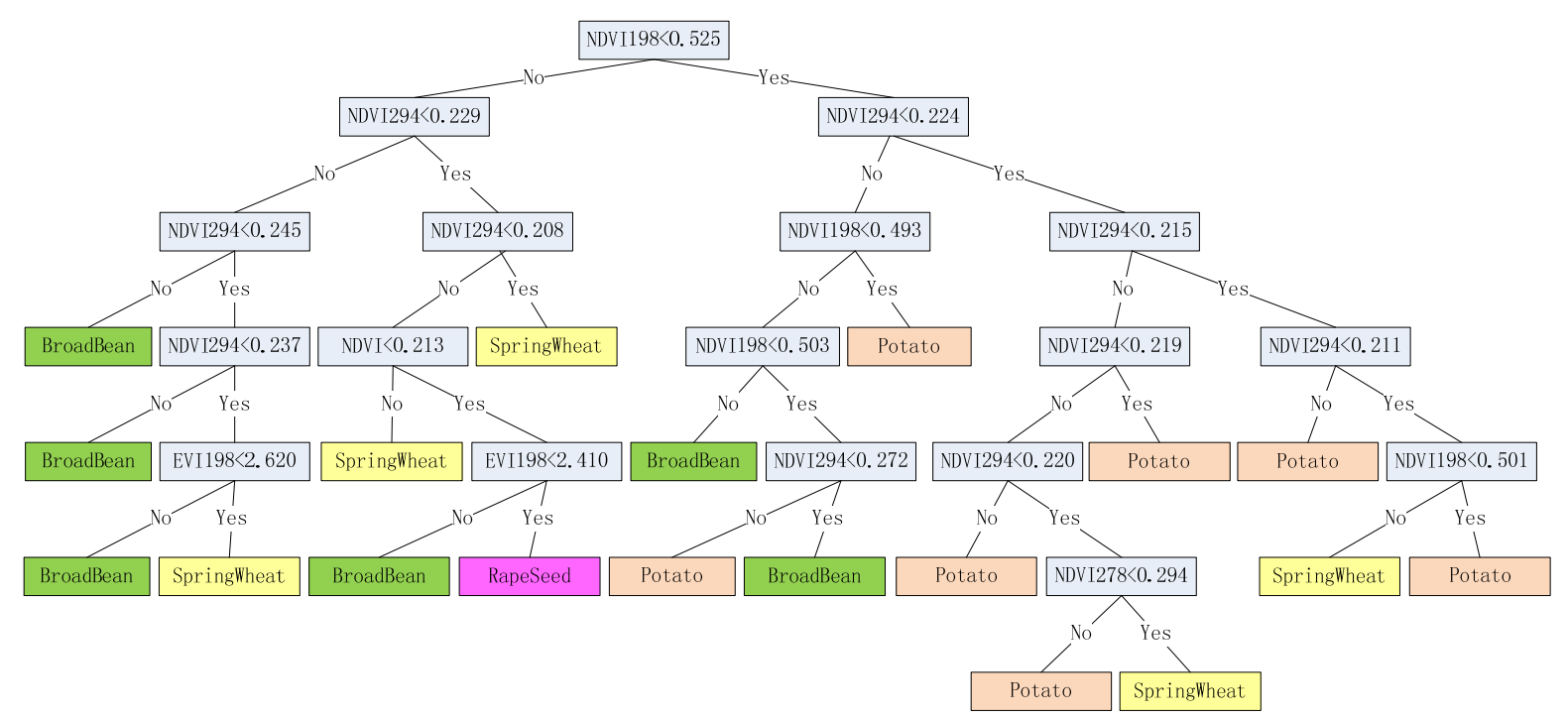

Figure 4. Decision tree used as prediction rules for crop identification within unknown crop type pixels

\subsection{Verifying and Accuracy Assessment}

A crop classification map (Figure 5) is generated by masking the result map of decision tree with a cropland map in 2010, with goals of improving classification accuracy as well as save processing time. Accuracy verification is followed by calculating the correct rate of identification within the sampled plots. This accuracy varies among five crops this paper focused, in overall, crops that planted in a relatively larger continuous scales, like spring wheat, potato and rapeseeds, can be identified with an acceptable accuracy, which is $76.92 \%, 64.29 \%$, and $72.73 \%$ in sequentially. However, crops that planted either dispersedly (like broad bean) or too small sacles (like barley, which is planted in margin lands of less than 0.5 ha, where plots of meeting image resolution requirements are hard to find, that's why only two plots were sampled for barley in this test), are hard to be differentiated, which resulted in a pretty lower identification accuracy of them.

Beside this, the unknown area that can't be identified from this method remains about $56.3 \%$ compared to the total agricultural area $\left(8.36 \times 10^{4}\right.$ hectare $)$ extracted from land use/cover map of 2010 , and this area is also two times larger than statistical data of cropland $\left(4.58 \times 10^{4}\right.$ hectare $)$ in that year. That is to say the agricultural land in the land use/cover map of 2010 contains many other types of agricultural land other than cropland, which need to be excluded if applying this map for the purpose of screening cropland.

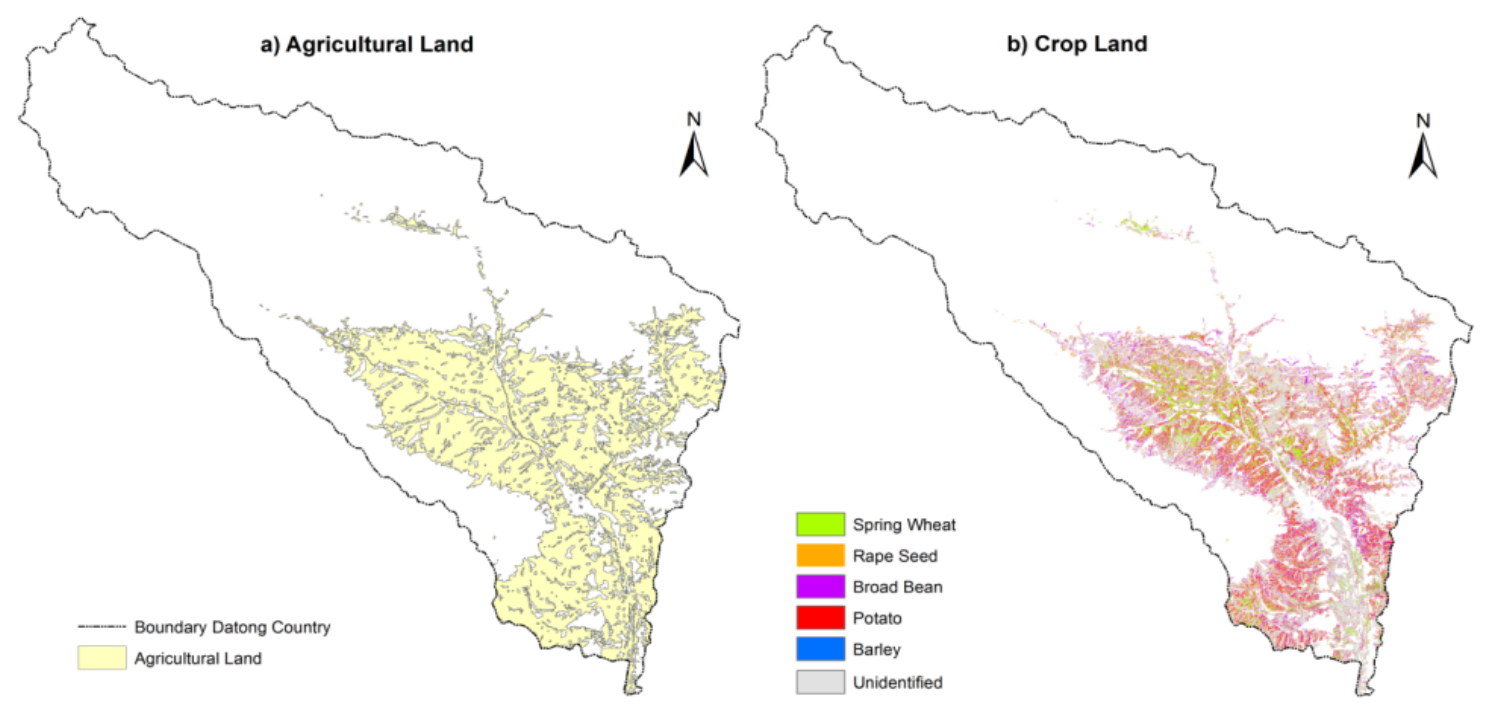

Figure 5. Crop classification map generated by using decision tree within agricultural land in research area 


\section{Discussions and Conclusions}

\subsection{Discussions}

1) Quantity relationship between amount of sampled plots (pixels) and accuracy of crop identification need to be investigated further for moving this methodology from useful to usable

In this work, a total amount of 134 pure single-crop pixels located in 38 plots was sampled as input data of known-crop type land, which including 5 crops planted over 2013 and 2015. Among which, three crops (spring wheat, potato and rapeseed) with sampling plots of above 6 , achieved a higher classification accuracy $(76.92 \%$, $64.29 \%$, and 72.73), while the other two crops (broad bean and barley) that have smaller sampling plots of less than 3, showed a poor recognition rates (below $50 \%$ ). This indicated that plenty of sampling plots is vital for a higher identification rate. However, it's hard to find plenty amount of qualified plots that can meet image resolution requirement in this region because of decentralized planting patterns and undulating terrain limitations on field size, which has become the major barrier for further application of this method.

One possible solution is to collect as much as possible croplands that involved in various demonstration projects, which is usually implemented by local governments with some useful information on crop planting, such as area, crop type, field management and planting planning etc. In addition, a more detailed sampling strategies should be taken if a quantitative relationship between sampling amount and identification accuracy is desired, which should not only take more factors into account, like elevation, slope, aspect and ecotypes etc., but also a grouping experiment focusing on revealing quantitative relationship should be conducted, such as 100 pixels, 1000 pixels and even more pixels for each crops and their potential identification accuracy.

2) Accurate information of field management on crop planting is essential for missing value replacement over years even within the same plots

There are always some images unqualified for establishing a time-series data set either because of contaminated images or missing of original images, so the replacement or supplement of a similar date images over years becomes one of most commonly used approaches to build a complete time-series data set. Therefore, the verification of crop types between replaced images and used images (usually the images of the same date over different years) are fundamental for such an approach, which requires detailed records of crop types and planting ranges over years. However, this approach has been evidenced difficult in this region not only because of crop rotation system that popular in this region, i.e., a two years rotation of spring wheat/potato-rapeseed or a three years rotation of spring wheat-rapeseed-potato, which results in different crops planted in the same plot over years. Besides, most of cropland that managed by farmers lacking records of fields management, which further narrowed potential sampling scale and resulted in a remarkable reduction on qualified crop land available for such a research.

There are two approaches recommended here for solving above problem, one is keeping on regular inspection on sampled plots so that the crop type and planting scale on the same plot over years can be recorded in accuracy; another one is seeking cooperation with agencies that running larger-scale crop lands and obtaining field records from them. However, both of those method will cost plenty of time and money input, which is unpractical for a short term research project.

3) Integrated knowledge of combining curve fitting algorithm into raster calculation processing is needed when a pixels-rooted curve fitting is required

Five sets of fitted crop curves and seasonal parameters were obtained from known-crop type pixels, with the original intention of using them as input data of constructing a decision tree for prediction crop types within testing pixels. However, due to the limitation of TIMESAT software which can generate only one fitted curve for whole scene of pixels within one operation, while not generate fitted curves for each pixel. Therefore, the pixel-rooted curve fitting process that served as an antecedent step of extracting seasonal parameters remained unavailable via TIMESAT software, where integrated techniques of computer compiling is needed if a pixel-rooted seasonal parameters is desired.

This may be achieved by integrating algorithms involved in curve fitting and seasonal parameters extraction into raster calculation process, where comprehensive knowledge of algorithm and computer compiling languages is needed, and an automatic workflow of this methodology proposed in this paper will be achieved by this way, which will eventually make this methodology becoming a practical tool for crop management and planning.

4) Some newly developed method and comparisons among methods is needed for meeting multiple requirements on crop identification accuracy and their application 
It is well known that traditional pixel-based analysis of remote sensing data will result in inaccurate identification of crop types due to pixel heterogeneity, mixed pixels, spectral similarity, and crop pattern variability. Some newly developed techniques (Peña-Barragán, Ngugi, Plant, \& Six, 2011; Zhong, Gong, \& Biging, 2012), such as object-based image analysis that integrated with decision tree algorithms, or phenology-based crop identification methods by combining multiple vegetation indices, textural features and crop phonology etc., have showed a stable performance in large scale crop classification. Such methods are worth trying in research area because of complexing terrain conditions, where technologies of reducing data dependency on ground observation and obtaining automatic crop calendars across years is highly desired.

\subsection{Conclusions}

The purpose of this study is to test the feasibility of identifying crop types in a mountainous agricultural region, by using time-series VIs as well as seasonal parameters and growth profiles, which can be derived from freely downloaded TM images at $30 \mathrm{~m}$ resolution. The results indicate that those crops (e.g., spring wheat, potato and rapeseed) that planted in a larger continuous ranges and have plenty of qualified sampled plots available, can achieve an average accuracy of about $70 \%$; while those either planted too dispersedly (e.g., inter-planted with other crops) or too smaller planting ranges will result in an insufficient qualified sampled plots and thus remains unrecognizable.

The value of this research lies in the schema it developed by integrating three key steps of VIs calculation and time-series building, growth curve fitting and seasonal parameter extracting, and generating a classification decision tree, into an automatically workflow that can be used as basic data of crop mapping and relative minoring activities, which is highly desired in this region. But constrained by several factors remained in this work, e.g. the limited investigation plots and shorter time-series data set obtained, computer compiling difficulty in generating fitted curves for each pixel etc., both the accuracy of crop identification and automatic level of this workflow have the potential to be improved in future.

The main conclusion of this work is list as below: i) The accuracy of classification is sensitive to the numbers of sampled plots, especially those of known crop-type plots and their spatial representative, thus the relationship between them need to be investigated further and a quantitative relationship will be helpful for any further application of such a methodology; ii) Accurate information of field management on crop planting is essential for missing value replacement over years, one feasible approach of obtaining ground-true observations is seeking cooperation from agencies that running larger scale crop lands; iii) Comprehensive knowledge of curve fitting and raster datasets processing is the key factor that affecting the seasonal parameters availability based on pixel level, resolving of this obstacle will enable the fulfillment of automatic workflow of the methodology proposed in this paper; iv) Some newly developed method are worth trying for better identification of crop types under complex environment, and comparisons among methods is needed for meeting various crop classification requirements and their application.

\section{References}

Agriculture and Animal Husbandry Bureau of DaTong County. (2013). Modern agriculture demonstration planning for Datong County in the 12th five-year period (2011-2015). Governmental Report. Retrieved from http://www.moa.gov.cn/ztzl/xdnysfq/fzgh/201301/t20130121_3204303.htm

Bannari, A., Morin, D., Bonn, F., \& Huete, A. R. (1995). A review of vegetation indices. Remote Sensing Reviews, 13(1-2), 95-120. https://doi.org/10.1080/02757259509532298

Bodart, C., Eva, H., Beuchle, R., Rašia, R., Simonettib, D., Stibiga, H. J., ... Acharda, F. (2011). Pre-processing of a sample of multi-scene and multi-date Landsat imagery used to monitor forest cover changes over the tropics. ISPRS Journal of Photogrammetry and Remote Sensing, 66(5), 555-563. https://doi.org/10.1016/ j.isprsjprs.2011.03.003

Boehmer, N. A. (1996). Vegetation indices for Landsat images. Proceeding of Southwest Symposium on Image Analysis and Interpretation (pp. 258-262). https://doi.org/10.1109/iai.1996.493763

Boryan, C., Yang, Z., Mueller, R., \& Craig, M. (2011). Monitoring US agriculture: the US Department of Agriculture, National Agricultural Statistics Service, Cropland Data Layer Program. Geocarto International, 26(5), 341-358. https://doi.org/10.1080/10106049.2011.562309

Brown, C., \& Waldron, S. (2013). Agrarian change, agricultural modernization and the modelling of agricultural households in Tibet. Agricultural Systems, 115, 83-94. https://doi.org/10.1016/j.agsy.2012.09.008 
Chen, H., \& Zhuang, D. (2012). Strategy to extract winter wheat and summer maize distribution based on time-series MODIS NDVI data. First International Conference on Agro-Geoinformatics (pp. 1-5). https://doi.org/10.1109/agro-geoinformatics.2012.6311609

Chen, J. M., Jönsson, P., Tamura, M., Gu, Z., Matsushita, B., \& Eklundh, L. (2004). A simple method for reconstructing a high-quality NDVI time-series data set based on the Savitzky-Golay filter. Remote Sensing of Environment, 91(3-4), 332-344. https://doi.org/10.1016/j.rse.2004.03.014

Cohen, W. B., \& Goward, S. N. (2004). Landsat's role in ecological applications of remote sensing. BioScience, 54(6), 535-545. https://doi.org/10.1641/0006-3568(2004)054[0535:Irieao]2.0.co;2

Fischer, A. (1994). A model for the seasonal variations of vegetation indices in coarse resolution data and its inversion to extract crop parameters. Remote Sensing of Environment, 48(2), 220-230. https://doi.org/10.1016/0034-4257(94)90143-0

Gong, Y., \& Shi, J. (2003). Northern hemispheric NDVI variations associated with large-scale climate indices in spring. International Journal of Remote Sensing, 24(12), 2559-2566. https://doi.org/10.1080/014311603100 0075107

Huete, A. R. (1988). A Soil-Adjusted Vegetation Index (SAVI). Remote Sensing of Environment, 25(3), 295-309. https://doi.org/10.1016/0034-4257(88)90106-x

Huete, A., Didan, K., Miura, T., Rodriguez, E. P., Gao, X., \& Ferreira, L. G. (2002). Overview of the Radiometric and Biophysical Performance of the MODIS Vegetation Indices. Remote Sensing of Environment, 83(1-2), 195-213. https://doi.org/10.1016/s0034-4257(02)00096-2

Jönsson, P., \& Eklundh, L. (2004). TIMESAT-A program for analyzing time-series of satellite sensor data. Computers and Geosciences, 30(8), 833-845. https://doi.org/10.1016/j.cageo.2004.05.006

Ke, Y., Im, J., Lee, J., Gong, H., \& Ryu, Y. (2015). Characteristics of Landsat 8 OLI-derived NDVI by comparison with multiple satellite sensors and in-situ observations. Remote Sensing of Environment, 164, 298-313. https://doi.org/10.1016/j.rse.2015.04.004

Lees, B. G., \& Ritman, K. (1991). Decision-Tree and Rule-Induction Approach to Integration of Remotely Sensed and GIS Data in Mapping Vegetation in Disturbed or Hilly Environments. Environmental Management, 15(6), 823-831. https://doi.org/10.1007/bf02394820

Odebweller, J. B., \& Johson, K. I. (1984). Crop Identification using Landsat temporal-spectral profiles. Remote Sensing of Environment, 14(1-3), 39-54. https://doi.org/10.1016/0034-4257(84)90006-3

Oetter, D. R., Cohen, W. B., Berterretche, M., Maiersperger, T. K., \& Kennedy, R. E. (2001). Land cover mapping in an agricultural setting using multi-seasonal Thematic Mapper data. Remote Sensing of Environment, 76(2), 139-155. https://doi.org/10.1016/s0034-4257(00)00202-9

Oteros, J., García-Mozo, H., Botey, R., Mestre, A., \& Galán, C. (2015). Variations in cereal crop phenology in Spain over the last twenty-six years (1986-2012). Climatic Change, 130(4), 545-558. https://doi.org/ 10.1007/s10584-015-1363-9

Pal, M., \& Mather, P. M. (2003). An assessment of the effectiveness of decision tree methods for land cover classification. Remote Sensing of Environment, 86(4), 554-565. https://doi.org/10.1016/s0034-4257 (03)00132-9

Patel, J. H., \& Oza, M. P. (2014). Deriving crop calendar using NDVI time-series. The International Archives of the Photogrammetry, Remote Sensing and Spatial Information Sciences, XL-8, 869-873. https://doi.org/10.5194/isprsarchives-xl-8-869-2014

Peña-Barragán, J. M., Ngugi, M. K., Plant, R. E., \& Six, J. (2011). Object-based crop identification using multiple vegetation indices, textural features and crop phenology. Remote Sensing of Environment, 115(6), 1301-1316. https://doi.org/10.1016/j.rse.2011.01.009

Reed, B. C., Brown, J. F., Vanderzee, D., Loveland, T. R., Merchant, J. W., \& Ohlen, D. O. (1994). Measuring phenological variability from satellite imagery. Journal of Vegetation Science, 5(5), 703-714. https://doi.org/10.2307/3235884

Roy, D. P., Wulder, M. A., Loveland, T. R., Woodcock, C. E., Allen, R. G., Anderson, M. C., .. Zhu, Z. (2014). Landsat-8: Science and product vision for terrestrial global change research. Remote Sensing of Environment, 145, 154-172. https://doi.org/10.1016/j.rse.2014.02.001 
Sakamoto, T., Yokozawa, M., Toritani, H. \& Ohno, H. (2005). A crop phenology detection method using time-series MODIS data. Remote Sensing of Environment, 96(3-4), 366-374. https://doi.org/10.1016/ j.rse.2005.03.008

Shao, Y., Lunetta, R. S., Ediriwickrema, J., \& Iiames, J. (2010). Mapping Cropland and Major Crop Types across the Great Lakes Basin using MODIS-NDVI Data. Photogrammetric Engineering and Remote Sensing, 76(1), 73-84. https://doi.org/10.14358/pers.76.1.73

Simonneaux, V., Duchemin, B., Helson, D., Er-Raki, S., Olioso, A., \& Chehboun, A. G. (2008). The use of high-resolution image time series for crop classification and evapotranspiration estimate over an irrigated area in central Morocco. International Journal of Remote Sensing, 29(1), 95-116. https://doi.org/10.1080/ 01431160701250390

Stehman, S. V., Sohl, T. L., \& Loveland, T. R. (2005). An evaluation of sampling strategies to improve precision of estimates of gross change in land use and land cover. International Journal of Remote Sensing, 26(22), 4941-4957. https://doi.org/10.1080/01431160500222632

Verbesselt, J., Hyndman, R., Newnham, G., \& Culvenor, D. (2010). Detecting trend and seasonal changes in satellite image time series. Remote Sensing of Environment, 114(1), 106-115. https://doi.org/10.1016/j.rse.2009.08.014

Wall, L., Laricque, D., \& Leger, P. M. (2008). The early explanatory power of NDVI in crop yield modelling. International Journal of Remote Sensing, 29(8), 2211-2225. https://doi.org/10.1080/01431160701395252

Wardlow, B. D., \& Egbert, L. S. (2008). Large-area crop mapping using time-series MODIS $250 \mathrm{~m}$ NDVI data: An assessment for the U.S. Central Great Plains. Remote Sensing of Environment, 112(3), 1096-1116. https://doi.org/10.1016/j.rse.2007.07.019

White, M. A., Hoffman, F., Hargrove, W. W., \& Nemani, R. R. (2005). A global framework for monitoring phenological responses to climate change. Geophysical Research Letters, 32(4), L04705. https://doi.org/10.1029/2004GL021961

Xu, Q., Yang, G., Long, H., \& Wang, C. (2013). Crop Discrimination in Shandong Province Based on Phenology Analysis of Multi-year Time Series. Intelligent Automation \& Soft Computing, 19(4), 513-523. https://doi.org/10.1080/10798587.2013.869109

Yang, Z., Di, L., Yu, G., \& Chen, Z. (2011). Vegetation condition indices for crop vegetation condition monitoring. 2011 IEEE International Geoscience and Remote Sensing Symposium, 58(11), 3534-3537. https://doi.org/10.1109/igarss.2011.6049984

Zhang, L., Zhang, Y., Yan, J., \& Wu, Y. (2008). Livelihood diversification and cropland use pattern in agro-pastoral mountainous region of eastern Tibetan Plateau. Journal of Geographical Sciences, 18(4), 499-509. https://doi.org/10.1007/s11442-008-0499-1

Zhong, L. H., Gong, P., \& Biging, G. S. (2012). Phenology-based Crop Classification Algorithm and its Implications on Agricultural Water Use Assessments in California's Central Valley. Photogrammetric Engineering \& Remote Sensing, 78(8), 799-813. https://doi.org/10.14358/pers.78.8.799.

Zhong, L., Hawkins, T., Biging, G., \& Gong, P. (2011). A phenology-based approach to map crop types in the San Joaquin Valley, California. International Journal of Remote Sensing, 32(22), 7777-7804. https://doi.org/10.1080/01431161.2010.527397

\section{Copyrights}

Copyright for this article is retained by the author(s), with first publication rights granted to the journal.

This is an open-access article distributed under the terms and conditions of the Creative Commons Attribution license (http://creativecommons.org/licenses/by/4.0/). 